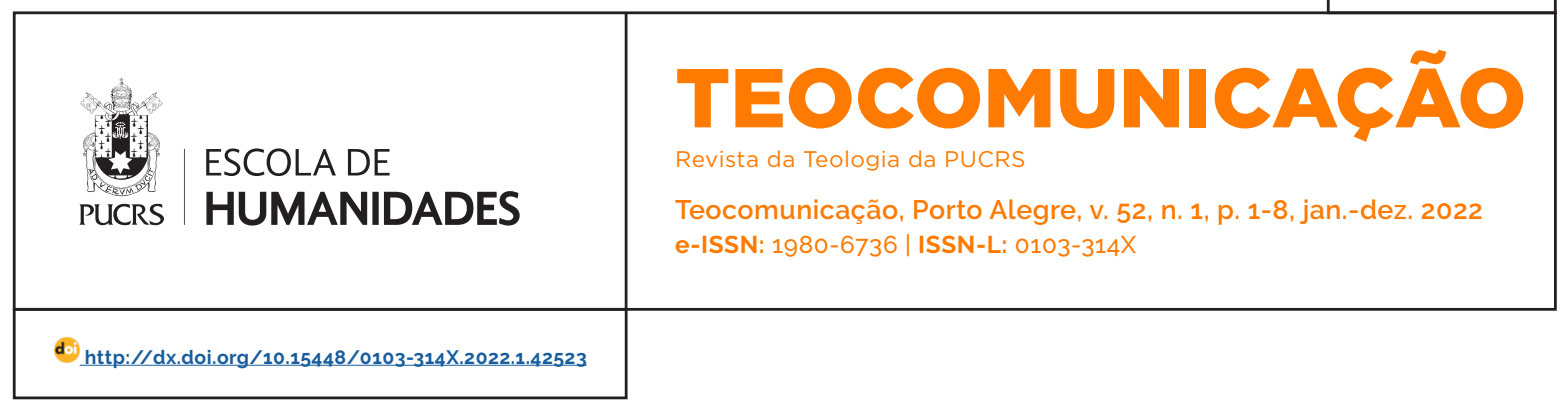

SEÇÃO: ARTIGOS LIVRES

\title{
Interpelações pastorais à teologia e à eclesiologia no universo pós-pandemia
}

\author{
Pastoral interpellations to theology and ecclesiology in the post-pandemic universe \\ Interpelaciones pastorales a la teología y la eclesiología en el universo pospandemia
}

\section{Reuberson Rodrigues \\ Ferreira $^{1}$}

orcid.org/0000-0001-6760-8027

reubersonferreira@yahoo.com.br

Recebido em: 28 dez. 2021. Aprovado em: 13 jan. 2021. Publicado em: 21 fev. 2022.

\section{(c) (1)}

Artigo está licenciado sob forma de uma licença Creative Commons Atribuição 4.0 Internacional.
Resumo: O presente artigo tem por objetivo arguir algumas interpelações à ciência teológica e à eclesiologia no panorama pós-pandemia. Quer-se interrogar sob o prisma da teologia e da eclesiologia, qual a interpretação possivel para os desafios vividos durante a pandemia. Igualmente quais possibilidades, desafios e limites urgem uma reflexão acurada a partir desses dois campos do saber. Refletir-se-á sobre a pandemia e as pandemias que ela revelou e, por fim, serão pontuados alguns elementos que se apresentam como desafios e possibilidades à teologia ante a crise que se vive.

Palavras-chave: Teologia. Eclesiologia. Pandemias. Possibilidades. Limites.

Abstract: This article aims to argue some interpellations to theological science and ecclesiology in the post-pandemic panorama. We want to question, from the perspective of theology and ecclesiology, what is the possible interpretation for the challenges experienced during the pandemic. Equally what possibilities, challenges and limits urge an accurate reflection from these two fields of knowledge. It will reflect on the Pandemic and the pandemics that it has revealed and, finally, some elements that present themselves as challenges and possibilities for theology in the face of the crisis we are experiencing will be punctuated. Keywords: Theology. Ecclesiology. Pandemics. Possibilities. Limits.

Resumen: Este artículo tiene como objetivo argumentar algunas interpelaciones a la ciencia teológica y la eclesiología en el panorama pospandemia. Queremos cuestionar, desde la perspectiva de la teología y la eclesiología, cuál es la interpretación posible para los desafíos vividos durante la pandemia. Igualmente qué posibilidades, desafíos y limites urgen a una reflexión certera desde estos dos campos del saber. Se reflexionará sobre la Pandemia y las pandemias que ha revelado y, finalmente, se puntualizarán algunos elementos que se presentan como desafíos y posibilidades de la teología frente a la crisis que estamos viviendo. Palabras clave: Teología. Eclesiología. Pandemias. Posibilidades. Limites.

\section{Introdução}

À guisa de introdução podemos recorrer à tragédia teutônica, escrita em dois atos por Goethe (1749-1832), intitulada "Fausto". Ela, entre outros elementos, nos apresenta um dilema, em certa medida, pertinente a uma reflexão acerca dos desafios impostos à teologia com a assunção da pandemia causada pelo vírus SARS-CoV-2.

O protagonista desse texto de Johann Goethe, homônimo ao título da obra, é um homem, embora muito descontente com isso, imensamente ilustrado. Uma pessoa bem-formada, um doutor medieval. Insatisfeito 
com a formação intelectual e acadêmica obtida ao longo de sua vida, ele põe-se a reclamar das ciências conquistadas outrora, mas que agora causam-lhe dissabores. Entre elas a teologia que era ensinada nas universidades medievais, ao lado de outras ciências liberais que formavam os doutores no medievo (Filosofia, Artes, Direito e Medicina). Fausto, ante seus inúmeros saberes, está disposto a qualquer coisa por um saber amplo, dilatado e profundo.

Criticando todos os saberes que havia recebido, acerca da teologia, desponta uma afirmação. Nas ciências teológicas, "[...] há mil caminhos falsos difíceis de evitar; há mil peçonhas tão ruins, que as extrair o remédio é [...] foro impossivel [...]. Nessa ciência, o mais seguro é não pensar por si, mas jurar pelo mestre" (GOETHE, 2012, p. 105). Tal frase é dita a um jovem que busca no sábio doutor, conselhos em vista de aprofundar seus conhecimentos. Ela parte da boca de Mefistófeles, personificação do mal que havia assumido o lugar de Fausto e estava travestido com o barrete e a capa de doutor, visto que Fausto havia partido em busca de um saber que desse sentido à sua vida. Como alternativa ao descontentamento como todas as ciências, inclusive com a teológica, como expressa aquela máxima, Fausto põe em xeque sua alma em uma aposta com o demônio. Em troca exige um saber que faça sentido, na verdade um amor e aventura-se em busca de tal em uma espécie de outra existência. Deve-se dizer que, nem o saber perfeito tampouco o amor será alcançado.

Desse texto, a despeito das interpretações literárias que a ele possam ser impressas, pode-se entender que para o doutor Fausto, qualquer ciência deve, antes de mais, dotar a realidade de sentido, sob o risco de ser preterida. Apresentar razões para viver, em última instância, gozar de um amor, de uma paixão que lhe torne plausivel. Assim, ciência, consoante à leitura que fazemos da obra de Goethe, deve ser elemento capaz explicar e dar sentido à realidade.

Essa tragédia de versos rimados e métricos, plastifica uma crítica que pode ser aplicada às ciências na atualidade. Qualquer ciência despro- vida de uma razão causal que ofereça sentido à vida, à pesquisa e ao entendimento de mundo, seria desnecessária. A teologia, citada em "Fausto" como uma das ciências do universo acadêmico por ele apropriadas, em nosso tempo, tem que se apresentar com argumentos que imprimam sentido à sua existência e legitimidade epistemológica à sua produção

No campo da prática teológica e da incidência sobre vida concreta das pessoas, a teologia precisa imprimir sentido à história, divisar desafios e propor possibilidades. Essa ideia (dotar de sentido) à luz dos acontecimentos recentes - crises geradas pela pandemia - que se quer aprofundar nesta reflexão. Poderiamos interrogar, sob o prisma da teologia, qual o sentido destes tempos dificeis e pandêmicos que vivemos? Quais limites, desafios e possibilidades do bem comum em tempos de pandemia (e pós), podem despontar do ponto de vista teológico? Essas duas questões buscar-se-á responder ao longo deste texto. Assim, metodologicamente este artigo apresentará em sua primeira parte uma ligeira digressão para aludir, evitando confusões e ou imprecisões, o que esperar da teologia, seu locus e o modus de operação. Na segunda parte, refletiremos sobre a pandemia e as pandemias que ela revelou e, por fim, pontuaremos alguns elementos que se apresentam como desafios e possibilidades à teologia ante a crise que vivemos.

\section{Teologia: locus e modus de atuação}

Etimologicamente, a palavra teologia, que no principio não era usada nos mesmos modos que hoje e nem com a mesma finalidade (WACHER, 1993. p. 857), significa: Theo (Deus) + Logia (Ciência, saber). Desse modo, a reflexão teológica refere-se por uma via ou outra a Deus. Etimologicamente ela significa um "discurso, um saber, uma palavra, uma ciência de ou sobre Deus" (LIBÂNIO; MURAD, 2001, p. 63).

Aprofundando a questão e delimitando o lugar, da teologia, seu campo de ação e universo de reflexão, pode-se dizer que é, a um só passo e paradoxalmente, amplo e restrito. Restrito, porque é a ciência que reflete sobre Deus, sobre a 
fé em Deus, portanto, um campo determinado. Amplo, pois entendemos, Deus como razão última de todas as coisas, deste modo, tudo que se relaciona a Deus pode ser objeto de ação e de investigação do ponto de vista teológico.

Na clássica definição atribuida a Santo Tomás de Aquino, o objeto material da teologia é Deus. Entretanto, como não é possivel estudar diretamente um objeto que não vemos e não tocamos diretamente, estuda-se Deus a partir da sua revelação. No cristianismo isto se dá a partir da revelação de Deus na Bíblia e na Tradição. Assim, podemos dizer que o objeto formal da teologia é o modo como se reflete sobre Deus revelado em Jesus Cristo. A ciência teológica, portanto, propõe-se refletir sobre Deus enquanto Deus revelado.

O que configura uma reflexão teológica propriamente dita? Uma reflexão teológica cristã, largos traços, configura-se por uma "meditação" sobre o Deus revelado em Jesus Cristo. Esse é o ponto de partida, o elemento fundante. Todavia, para que determinado assunto atinja a estatura de reflexão teológica faz-se necessário o uso daquilo que chamamos de "mediação hermenêutica teológica" ou seja, as luzes da revelação, da tradição e/ou do "Magistério" Exemplificando, dado um tema - pandemia no caso nosso - para que ela seja refletida nos moldes teológicos, faz-se necessário que ela seja lida à luz da revelação, da tradição e do Magistério. Somente assim é possivel ter uma reflexão teológica sobre o assunto, apresentando-lhe uma interpretação, um sentido à luz da fé.

Transformando essa ideia em uma pergunta, pode-se dizer: o que, à luz da revelação e da tradição, a pandemia diz de Deus ou da nossa fé em Deus? Tornando mais simples, e colocando em uma linguagem popular e do senso comum, pode-se resumir na seguinte frase: "O que Deus quer nos dizer com esse fato?" São essas perguntas, respondidas à luz das mediações hermenêuticas (revelação, tradição e magistério) que possibilitam o surgimento daquilo que chamamos de teologias do genitivo ou de novos enfoques teológicos (LIBÂNIO; MURAD, 2001, p. 63). Nota-se que esses enfoques são contextuais - decorrem de uma situação concreta - e querem à luz da fé interpretar e dar sentido a questões humanas. Dessas interpelações surgem reflexões teológicas, como a teologia feminista, teologia da libertação, teologia do sofrimento. Observa-se, assim, que a finalidade última é dar um sentido à luz da revelação do Deus revelado em Jesus Cristo, para uma realidade concreta.

Alguns, porém, poderiam aventar que se o Deus revelado em Jesus Cristo é objeto de fé apenas para os cristãos, dotar de sentido uma realidade que atinge crentes e não crentes apenas nessa perspectiva poderia ser excludente. Contudo, convém recordar que, sobretudo com os movimentos teológicos pós-vaticano II, Cristo é apresentado, diriamos, em um movimento cósmico, uma salvação que é aberta a todos. Desse modo, todos estariam inclusos, pois o objetivo último do Deus revelado em Jesus, além da salvação, é garantir a vida plenamente humana para todos - potencializar o ser humano.

Desse modo, regressamos à introdução, ao dilema de Fausto da busca por um saber dotado de sentido. A teologia, dentro do seu raio de ação - a partir da revelação de Deus em Jesus Cristo deve dotar de sentido a realidade como um todo, mas em específico deve imprimir de sentido da realidade sofrida da pandemia, causada pelo vírus causador da SARS-CoV-2, o coronavírus. Antes, porém, convém deixar claro que não há somente uma pandemia. Há uma pandemia que revelou outras várias realidades pandêmicas.

\section{Pandemias: não há uma só pandemia}

A existência da pandemia causada pelo coronavirus é um fato. Ela é palpável, sentida sofrida e "chorada" diretamente por muitos de nós. Nos dias iniciais do ano de 2020, constatou-se na China o surgimento de um novo tipo de coronavirus, nomeado pouco depois pela Organização Mundial de Saúde de COVID-19 (OMS, 2020). Menos de dois meses de sua origem, foi tipificado como uma pandemia mundial. Após contágio expressivo no país Asiático e larga difusão na Itália, na Espanha, na França, na Alemanha e no 
Vaticano, entre outros, foram decretados estado de calamidade pública nesses países assolados por vertiginosas mortes. Em face dessa situação, a seu ritmo, em cada nação autoridades políticas decretaram modalidades de quarentena. A Igreja, nessas regiões, seguiu o mesmo caminho, adotando normas de restrição de mobilidade e/ou inibição de aglomeração, em atenção aos seus governos, como testemunha, por exemplo, a posição do episcopado italiano (CONFERENZA EPISCOPALE ITALIANA, [2020]).

No Brasil, o primeiro caso de COVID-19 foi detectado em 26 de fevereiro de 2019 (MINISTÉRIO DA SAÚDE, [2020]) e a primeira morte foi confirmada em 14 de março de 2019 (RIBEIRO; CAMBRICOLI, 2020). Nesse interim, as autarquias governamentais de saúde estaduais, municipais e federais iniciaram um processo de consolidação de normas para o enfrentamento da pandemia que havia se estabelecido no país. Malgrado à desarticulação entre os niveis de poder e à postura negacionistas assumidas, ações de combate à pandemia foram executadas. Atualmente, são 219 milhões de casos com 455 milhões de mortes. No Brasil, mais de 600 mil mortes com 22 milhões de infectados. $76 \%$ dos brasileiros foram vacinados ao menos com a primeira dose e 60\% foram totalmente imunizados.

Não obstante à clareza de que a pandemia da COVID-19 é real, devemos também admitir que ela não é a única pandemia, e que ela revelou a amplitude a extensão de outras pandemias. Há, sem pessimismos, uma pandemia de pandemias. O Papa Francisco, em 2015, na Enciclica Laudato Si, antecipando e constando aquilo que a pandemia provou, ao falar da crise ambiental, argumentava que não havia várias crises, mas uma única e complexa crise socioambiental (LS 139). Nesse sentido, Francisco questiona "o que está acontecendo com nossa casa?" (LS 17). Ele apresenta seis pontos que confirmam essa crise de proporções maiores (poluição e mudanças climáticas, a crise hídrica, a perda da biodiversidade, a deterioração da qualidade de vida humana e a degradação social, a fraqueza e a diversidade das opiniões), dos quais apresentamos dois: po- luição e mudanças climáticas e deterioração da qualidade de vida humana e degradação social e desigualdade planetária.

O Papa apresenta a poluição, a cultura do descarte e a questão climática como facetas da crise que assola a casa comum. De fato, a produção de insumos tóxicos associada a uma economia capitalizada, bem como o lixo excessivo, afeta populações inteiras, causando muitas mortes e desfigurando cenários. Essa cultura do descarte, repercute na vida das pessoas que não raras, quando não mais úteis são tratadas como substituíveis. A vida importa enquanto tem valor agregado, enquanto produz. Nesse cenário frágil, pobres idosos, tornam-se desnecessários, irrelevantes.

Outro aspecto dessas crises, segundo o Papa Francisco, tem seu matiz na desigualdade planetária. Essa condição afeta a qualidade de vida, sobretudo dos mais pobres. Projetos socioeconômicos são pensados a partir dos grandes núcleos visando o lucro e a comodidade, não raro sem levar em consideração as necessidades daqueles que são mais empobrecidos, concorrendo para que não haja acesso à qualidade de vida. Essa desigualdade financeira, aventada pelo papa ficou explícita durante a pandemia. Países mais ricos e mais desenvolvidos, bem-conduzidos, estabeleceram políticas de prevenção ao contágio de proteção aos empobrecidos, garantindo conforto e saúde para os seus. Países empobrecidos, não gozaram da mesma sorte e centenas de pessoas foram vitimadas pela COVID-19.

Para além da análise do Papa, dentro dessas crises, ainda podemos relatar a crise migratória originada por diversas razões, desde guerras civis, até a necessidade busca de melhor qualidade de vida, levando a uma procura em massa por novos destinos; igualmente, podemos falar da crise de valores éticos e morais. Enfim, há uma pandemia acentuada dentro da pandemia protagonizada pelo vírus SARS-CoV-2, causador da covid. Tendo como fundo essa crise econômica, social, política e moral, a teologia deve ater-se no espectro da luz de seus postulados, dotar a realidade de sentido. 
3 Desafios teológicos e eclesiológico pós-pandemia

\section{1 "O delírio da onipotência"}

Diante da crise humana, social, política e sanitária que atualmente vivemos, um primeiro desafio imposto à teologia, conseguintemente daqueles que dela operam quer direta ou indiretamente, no labor pastoral ou na formação de homens e mulheres com atuação direta na vida de fé das pessoas, é o de contraditar a ideia de "onipotência" humana.

O racionalismo moderno, a razão instrumental, particularmente no Século XIX, apesentou-se como a panaceia do mundo. Negou pressupostos metafísicos e arrogou a si a exclusividade da interpretação e condução do destino e da felicidade humana. Essa condição, de algum modo, levou a humanidade e sua fé absoluta em si, a exageros. As guerras dos séculos passados golpearam essa certeza, mas não a aniquilaram.

Atualmente, em um contexto de antropocentrismo acentuado e em uma sociedade regida pelo paradigma tecnocrático, embora haja vozes divergentes, a ideia de onipotência da técnica e do ser humano grassam na atitude de muitas pessoas. Tal ideia corporifica-se, entre outros, na negação dos efeitos nefastos que o desenvolvimento sem planejamento ou preservação causam na terra - aquecimento global, descongelamento de geleiras. Igualmente, apresenta-se na negação da crise social e sanitária que a pandemia causou. Acredita-se ou presume-se como necessária a morte de alguns ou crer-se que apenas uma casta (evolucionismo) deve sobreviver.

Contudo, essa cultura contrasta com o projeto de Deus, que confiou à humanidade o mundo como um lugar de cuidado e a vida de todos como uma dádiva. Nesse sentido que é necessário, combater a cultura da onipotência humana. O cardeal Raniero Catalamessa, na Sexta-Feira Santa de 2020, cunhou a expressão delírio da onipotência:

A pandemia de corona vírus nos despertou bruscamente do perigo maior que sempre correram os indivíduos e a humanidade, o

\begin{abstract}
do delírio de onipotência. Temos a ocasião - escreveu um conhecido Rabino judeu - de celebrar este ano um especial êxodo pascal, o "do exilio da consciência" [3]. Bastou o menor e mais informe elemento da natureza, um virus, para nos recordar que somos mortais, que o poderio militar e a tecnologia não bastam para nos salvar. "Não dura muito o homem rico e poderoso: - diz um salmo da Bíblia - é semelhante ao gado gordo que se abate" (SL 49,21). E é verdade (CATALAMESSA, [2020]).
\end{abstract}

Assim, é tarefa urgente de todos, à luz da teologia, combater o delírio da onipotência. Como fazê-lo? À luz da teologia da cruz e da teologia da criação. É com a teologia da cruz que o onipotente é aquele que morre para salvar. Portanto, se faz necessário aguçar a consciência da contingência humana e da dignidade da morte, que não dever ser nem trágica, nem indiferente. É com a teologia da criação a consciência de que somos criados e que a criação divina, que nos inclui, deve ser cuidada, pensada com critérios de conservação, autopreservação e desenvolvimento sustentável.

\section{2 "Hermenêutica da ação de Deus no Mundo"}

Um segundo desafio é a uma "Hermenêutica da ação de Deus no mundo". Em outras palavras, postular uma correta apresentação da ação de Deus na história. Transformado em uma pergunta, ensinar: de que modo Deus age no mundo?

Com a inesperada assunção da pandemia da COVID-19 e com a morte de milhares de pessoas, repetiam-se em muitos lugares, as mesmas perguntas que se faziam em Auschuwitz, como: Deus, onde está? Nesse cenário divisa-se uma oportunidade e um desfio para aqueles que operam quer direta ou indiretamente a ciência teológica, ou seja, como apresentar a atuação de Deus no mundo.

Há, embora seja uma avaliação generalizante, duas grandes perspectivas sobre a ação de Deus no mundo. De um lado, aqueles que julgam que se Deus existe, ele não interfere na realidade humana e tudo é casualidade, explicado a partir de uma lógica da fenomenologia. De outro, há aqueles que defendem que Deus age, intervém na realidade humana e para provar isso evocam 
e/ou prometem cura, milagres, graças. Com efeito, em uma visão pré-moderna de mundo, onde as grandes questões eram explicadas a partir da religião a noção de um Deus intervencionista era muito mais plausivel e aceita por outros. $\mathrm{Na}$ modernidade, as coisas mudaram, a religião deixou de ser o eixo que explica o mundo e, em casos graves como o da pandemia, os pedidos de intervenção divina podem ser lidos como confirmadores de que Deus está indiferente ao mundo, caso suas súplicas não estejam atendidas. Cria-se um cenário fecundo para um ateísmo, deísmo ou indiferentismo à questão religiosa (KUZMAM, 2011).

Assim, no atual cenário pandêmico que vivemos, um desafio aqueles que por elementos teológicos se movem, é apresentar uma correta interpretação da ação de Deus no mundo. Ele não é, embora esteja próximo, apenas responsável por responder nossas fraquezas. Esse fato porque tal condição limitaria Deus. Antes o contrário, o Deus cristão é amor e nos criou livremente, sua ação no mundo passa pela liberdade humana. "Logo a solução para os nossos problemas está no correto uso de nossa condição - livres - e na harmonia das relações entre o ser humano, o mundo e Deus (KUZMAM, 2011, p. 231). Um Deus intervencionistas - sem negar a providência divina - não é marca distintiva da ação divina. Deus age por amor, não em uma relação de troca de favores. "O Deus cristão, pregado por Jesus, é um Deus que atua a partir de dentro, que se coloca ao lado, que está junto, que serve e que pelo seu amor pretende despertar no ser humano a vontade de servir e amar" (KUZMAM, 2011, p. 232).

Deus não atua na morte, mas está ao lado dos que morrem. Deus não atua para que a pandemia se apresente, mas está ao lado daqueles que, no uso da sua liberdade, exercem a capacidade de produzir condições de restabelecimento da saúde. Condição essa - saúde - que também foi violada pela liberdade e outro ser humano.

Assim, é tarefa urgente de todos, à luz da teologia, combater o delírio, a ideia de um Deus intervencionista. Como fazê-lo? Apontado que a atuação de Deus - sem negar a providência divina - dá-se na liberdade, pois ele nos criou por amor, livres. Fundamentar a relação com Deus, no desejo de buscar o transcendente e não simplesmente do escambo.

\subsection{Desafios eclesiológicos: a questão Litúrgica}

No contexto da pandemia, o debate sobre as celebrações (cultos/ missas) ocupou lugar central. Na perspectiva católica, atitudes variadas foram assumidas diante desse cenário. Algumas posições foram protagonizadas. Desde a virtualização das celebrações com participação ativa até as campanhas que pressionavam pelo direito de comungar, muitos caminhos foram trilhados. Assim, entendemos que em âmbito prático dois aspectos impõem-se como desafio à teologia e aos operadores da ciência teológica no universo eclesiológico e, sobretudo, litúrgico, a saber: a comunhão Eucarística e a liturgia doméstica.

\subsubsection{Eucaristia: do consumir hóstia e comunhão eucarística}

Esta pandemia revelou que, na busca de ser presença na vida das pessoas, excesso foram cometidos, no que diz respeito à Eucaristia. $O$ zelo rigorista para que as pessoas comungassem, levou a muitas ações como "Drive Thru"; "Delivery" ou "Eucharistic March" a bordo de carros abertos ou de helicópteros. Testemunhou-se, a olhos vivos, que para muitas pessoas, como advogou uma certa campanha nomeada "devolvam-nos a missa", viver a fé no ambiente interno de sua Igreja doméstica era algo anômalo. Ser desobrigado, por justa razão, do sacramento da Eucaristia, não os exortava a uma vida espiritual mais intensa. A noção de comunhão eclesial não era algo claro. Essa conduta, atesta que muitas pessoas não são formadas para serem Igreja, mas para estarem na Igreja - que não é mal nenhum quando precedido pelo ser.

Não obstante à reta intenção que tais ações podiam ter, esse fato escancarava uma formação deficiente. Atestava, de um lado, que alguns dos que presidem a eucaristia ou tomam parte do Sacramento, gozam de uma teologia pouco 
apurada sobre esse Sacramento (Unidade do sacramento). Negam, de igual modo, que o mesmo Cristo se manifeste de forma clara e real de outros modos, como, por exemplo, na Sagrada Escritura ou na caridade.

Associa-se a este tipo de conduta, o colocar em evidência a figura do sacerdote incitando, de certo modo, o nefasto veneno do clericalismo que, a um só passo, prescinde de outras formas metodológicas de evangelização e coloca o laicato como mero receptor do Evangelho, nunca como sujeito da evangelização.

Ante tal contexto, urge que a atuação pastoral, inspirada por uma reta teologia, deva operar uma profunda formação acerca do sacramento da Eucaristia. Deve-se migrar de um consumir hóstia a um fazer comunhão Eucaristica. A Eucaristia é a memória da vida de Cristo, aquele que deu a vida para que todos tivessem vida. Lutar para receber hóstia (Eucaristia) apenas para uma satisfação pessoal, não é o caminho de um reto entendimento do mistério celebrado. Ela é comunhão com Deus e com os outros. A ausência desse elemento ou a crença de uma dignidade acima da de outros para recebê-lo incide em um entendimento desvirtuado da Eucaristia, como celebram particularmente os cristãos católicos.

Assim, é tarefa urgente de todos, à luz da teologia, combater uma ideia turva do mistério Eucarístico. Como fazê-lo? Apresentando uma profunda catequese mistagógica sobre a Eucaristia. Do ponto de vista prático, como fazer isso? Como leigos, agentes e pastoral, acadêmicos, promover Semanas Eucarísticas. Servir-se dos roteiros de reunião comunitária para apresentar - modelo de novena - elementos teológicos da Eucaristia. Promover Semanas Eucaristicas e coibir discursos Eucarísticos alheios à realidade.

\subsubsection{Igrejas domésticas: da sinagoga ao templo}

A noção de Igreja doméstica ou familiar tem seus fundamentos na Sagrada Escritura, nas primeiras comunidades cristãs (CRÜSEMANN; REIMER, 2016, p. 179-190), as chamadas domus Eclesiae. Igualmente, as atuais paróquias, embora remodeladas pelo curso da história, têm sua origem fundamentada nesta ideia de Igreja-casa. (SOUZA, 2014, p. 164). Esse conceito é reassumido pelo Concílio Vaticano II (LG, 11). Largos traços, a definição mais recorrente de Igreja doméstica é da família como lugar de vivência e aprendizado da fé (LG, 11). Em sentido amplo, e recobrando a perspectiva biblico-histórico pode-se dizer que nelas, se tornava "possível a vida comunitária", a "acolhida dos pregadores itinerantes" e a formação de uma "plataforma missionária" (SOUZA, 2014, p. 164). Mais ainda, essas Igrejas-casas eram "espaços e experiências contraculturais" (CRÜSEMANN; REIMER, 2016, p. 187).

Nesse sentido, embora acossadas pelas circunstâncias de uma sociedade vivendo uma pandemia, pulularam sugestões que evocam a ideia de uma Igreja doméstica, particularmente nas determinações dos Bispos (FERREIA, 2011). Em um estudo realizado sobre as notas do episcopado para viverem o tempo de pandemia, nota-se que além da decisão de não promover eventos públicos com aglomerações, as sedes metropolitas exortam seus interlocutores a permanência em casa. Diante dessa condição sugere que aprendam a "recuperar o sentido de família como Igreja doméstica" (CNBB- NE3, [2020]) na qual os pais exercem o "oficio sacerdotal em relação aos filhos" (ARQUIDIOCESE DE SOROCABA, 2020, p. 1). Apontaram que o tempo pandêmico de mais recolhimento, seria momento para uma ampla "vivência comunitária", para os "exercícios de piedade", para "leitura orante da Palavra" ou para a "recitação da liturgia das horas".

Percebe-se que há insinuações para que as casas sejam ambientes de vivência concreta da fé. Igualmente, a sugestão da permanência em casa e da convivência dilatada, não obstante às dificuldades e o fato de não ser uma opção deliberada, reverte-se em um ato de contracultura, em um mundo que cada vez mais opõe-se à convivência e prima pelo individualismo.

Assim, nesse contexto pós-pandêmico é necessário para aqueles que operam a teologia ou dela se alimentam de uma devota e obstinada opção em vencer a dicotomia entre fé e vida, a 
Igreja-doméstica e a Igreja-instituição. Há aqui uma oportunidade concreta neste tempo (pós)-pandêmico, a de formar para uma experiência vivencial da fé. Deve-se formar para a noção que Igreja-doméstica e Igreja-institucional não são adversárias. O medo de que as pessoas deixem de ir à Igreja e celebrem em suas casas, não pode ser o mote da atuação pastoral. Antes o contrário. A Igreja doméstica deve convergir, como um corolário, para a Igreja-paroquial, lugar da vida comunitária mais dilatada, do banquete Eucaristico. Lugar do convivio entre irmãos! Pondera-se, contudo, que mesmo sendo uma opção viável, as Igrejas domésticas não podem degenerar-se "em guetos, em comunidades personalistas e em fontes de discórdia" (GUIERI, 2002, p. 205), pois assim, tornar-se-iam em símbolos da cultura vigente e não uma configuração eclesial à altura do Evangelho.

\section{Considerações finais}

Ao término desta reflexão nota-se que há uma série de desafios atinentes para sociedade como um todo. No caso particular da ciência teológica e daqueles que a operam (produzindo ou guiando-se por conceitos teológicos) a principal e mais importante atividade é a de dotar de um sentido a realidade que vivemos. Dotar de sentido, não quer dizer adorná-la de aspectos positivos, mas explicá-la no reto tom que the é necessário. Afiançando-lhe inteligibilidade e plausibilidade à luz da fé. Do exposto ao longo do artigo, nota-se bem mais do que a elaboração de conceitos, o imperativo é explicitá-los, apontá-lo de maneira veemente e clara.

\section{Referências}

AGUIRRE, Rafael. Del movimiento de Jesus a la Iglesia Cristiana; ensayo de exégesis sociológica del ristianismo primitivo. Estella: Verbo Divino, 2001.

CANTALAMESSA, Raniero. Pregação da Sexta-feira da Paixão na Basílica de São Pedro. In: Vatican News. Vaticano, 10 abr. 2020. Disponivel em: https://www. vaticannews.va/pt/vaticano/news/2020-04/pregacao-sexta-feira-paixao-raniero-cantalamessa-vaticano. html. Acesso em: 10 set. 2021

CRÜSEMANN, Marlene; REIMER, Ivoni Richter. Igrejas domésticas: lugar de acolhida, partilha e celebração na casa de mulheres. Caminhos, Goiânia, v. 14, n. 1, p.
179-190, jan./jun. 2016.

FERREIRA, Reuberson. A Pandemia e a Igreja Católica no Brasil: Algumas reflexões sobre a postura do episcopado Brasileiro para o enfrentamento da pandemia do covid-19. PLURA, Revista de Estudos de Religião [Journal for the Study of Religion], [S. I.], v. 12, n. 1, p. 136-153, 13 maio 2021.

FERREIRA, Reuberson Rodrigues; CARNEIRO, Vanessa Americano. Teologia e Universidade: considerações históricas e apontamentos para uma fecunda convivência. Caminhando, São Bernardo, SP, v. 22, n. 1, p. 51-66, jan./jul. 2017.

FRANCISCO. Laudato Si': Sobre o cuidado com a Casa comum (LS). São Paulo: Paulus: Loyola, 2015.

GOETHE, Johann Wolfgang von. Fausto. São Paulo: Montecristo editora, 2012. E-book.

KUZMAM, Cesar. Ação de Deus e sua realização na plenitude humana. In: Sanches, Mario; MIRANDA, Mario França. Age Deus no mundo: Múltiplas perspectivas teológicas. Rio de Janeiro: Editora PUC-RJ: Reflexão, 2012.

LIBÂNIO, João Batista; MURAD, Afonso. Introdução a Teologia: Perfil, Enfoques, Tarefas. 3. ed. São Paulo: Loyola, 2001.

MURAD, Afonso; GOMES, Paulo Roberto; Ribeiro, Súsie. A casa da Teologia: Introdução ecumênica à ciência da fé. São Paulo: Paulinas:Sinodal, 2017.

NOBRE, José Aguiar; CONCEIÇÃO, Elizeu. Pensar teologicamente a pandemia à luz de alguns escritos do Papa Francisco. ATeo, Rio de Janeiro, v. 25, n. 67, p. 41-66, jan./jun. 2021

SOUZA, Ney. Da Igreja doméstica à paróquia: Aspectos históricos das origens à atualidade da paróquia. Revista de Cultura Teológica, São Paulo, ano 22, n. 83, p. 164. jan./jun. 2014.

WACHER, Maria Teres. Teologia. In: DICIONÁRIO de Conceitos Fundamentais de Teologia. São Paulo: Paulus, 1993

\section{Reuberson Rodrigues Ferreira}

Mestre e doutorando em Teologia pela Pontificia Universidade Católica de São Paulo (PUCSP), em São Paulo, SP, Brasil. Professor no Instituto de Teologia João Paulo II, em Sorocaba, SP, Brasil.

\section{Endereço para correspondência}

Reuberson Rodrigues Ferreira

Instituto de Teologia João Paulo II

Av. Dr. Eugênio Salerno, 60

Centro, 18035-430

Sorocaba, SP, Brasil

Os textos deste artigo foram revisados pela Poá Comunicação e submetidos para validação do autor antes da publicação 